\title{
An algorithm development for producing of standard samples of explosives
}

\author{
(C) Alina R. Krivosheeva, ${ }^{+}$Anna V. Ananeva, ${ }^{*}$ Elvira N. Tarazova, \\ Tatiana A. Eneykina, and Rose F. Gatina \\ State Research Institute of Chemical Products. Svetlaya St., 1. Kazan, 420033. Republic of Tatarstan, Russia. \\ Phone: +7 (843) 564-38-92.E-mail:aneco_ic@mail.ru
}

*Supervising author; ${ }^{+}$Corresponding author Keywords: Standard samples, hexogen, octogen, ETN, trinitrotoluene, acetonitrile, requirements, quality, a metrology, an error, a container, a competence.

\begin{abstract}
The analysis of requirements for standard samples (SS) of the explosives' composition, aimed for improving of a determination (an identification) accuracy of the polluting emissions in the environment is given in the present work. As a result of the analysis of the requirements, defining the purpose of SS of the explosives' composition, the functions of the latter have been established; there are the measurement assurance and ensuring of measurement procedures of an explosives content in solutions, air, aqueous media, soils, surfaces washing-off, special products and also in various fields of a science and an industry, engaged in the production, an adjustment, a research and an operation of equipment for carrying out the quantitative chemical analysis and controlling the objects of the environment (signaling devices). There has been formed the circle of potential consumers of new SS of the explosives' composition, in which the enterprises of the industry of ammunition and special chemistry, subordinate organizations of the ministries of Russia (Ministry of Industry and Trade), higher educational establishments and also privately owned enterprises and organizations, carrying out the work related to the use of explosives are included; this circle imposes the requirements for SS quality and establishes a rating of the approved state SS (SSS). The purity degree of explosives (a base material fraction of total mass is no less than $99.5 \%$ by mass) and an acetonitrile (used as a solvent) (a water content is no more than $0.03 \%$ by mass) has been established in the course of carrying out of the analysis of the requirements for the initial materials. The ampoules, which are filled by means of the syringe and the glass medicine bottles of a general purpose were selected as a container in order to protect of SS specimen from the action of a complex of destructive factors, imposing the requirements for their storage conditions. In the course of studying of the necessity of SS material of the explosives' composition in different groups of purpose the volumes of a material in each individual ampoule (bottle) have been established, that is $5 \mathrm{~cm}^{3}$ and $20 \mathrm{~cm}^{3}$. It has been developed the algorithm for producing of SS of explosives' composition, meeting the aforementioned requirements.
\end{abstract}

\section{References}

[1] Law of the Russian Federation «On ensuring the uniformity measurements» No. 102-FL dated 26.06.2008. (russian)

[2] GOST 8.315 - 97. Standard samples of composition and properties of substances and materials. General provisions. Moscow: Standardinform. 1997. 100p. (russian)

[3] GOST ISO Guide 31-2014 Standard samples. The content of certificates and labels. Moscow: Standardinform. 2015. 16p. (russian)

[4] GOST ISO Guide 34-2014 The general requirements for a competence of manufacturers of standard samples. Moscow: Standardinform. 2015. 40p. (russian)

[5] M.Yu. Medvedevskikh, M.P. Krashenina, O.S. Shokhina. On the course of a development of a standard sample of solvent of 4,4-DDT. II-d International research conference "Standard samples in measurements and technologies". Yekaterinburg. 2015. P.89-92. (russian)

[6] GOST R53228-2008 Non-automatic scales. Part 1. The metrological and technical requirements. Tests. Moscow: Standardinform. 2010. 133p. (russian)

[7] GOST 1770-74 Laboratory graduated glassware. Cylinders, measuring glasses, flasks, test tubes. General specifications. Moscow: Standardinform. 2008. 20p. (russian) 
[8] GOST 4517-87 Reagents. Methods of preparation of auxiliary reagents and solutions, used in the course of an analysis. Moscow: Standardinform. 2016. 43p. (russian)

[9] GOST 6709-72 The distilled water. Specifications. Moscow: Standardinform. 2008. 11p. (russian)

[10] E.G. Rozantsev. A container and a package. E.G. Rozantsev. Moscow: MSIP. 1999. 203p. (russian)

[11] A.Ya. Legoshin. The glassblowing. A. Ya. Legoshin, L.A. Manuilov. Moscow: Higher school. 1985. 119p. (russian)

[12] GOST 7933-89 A cardboard for consumers' container. General specifications. Moscow: Publishing house of standards. $1990.11 \mathrm{p}$. (russian)

[13] «Regulations of transportation of dangerous goods by road»

[14] RF Government Regulation «On safety measures for the transportation of the dangerous goods by road» No. 372 dated 23.04.1994.

[15] GOST ISO/IEC 17025-2009. «General requirements for a competence of testing and calibration laboratories». Moscow: Standardinform. 2018. 27p. (russian)

[16] Law of the Russian Federation «On the technical regulation» No. 184-FL dated 27.12.2002.

[17] RIGS 93-2009 SMS. An evaluation of the metrological characteristics of standards samples. Moscow: Standardinform. 2011. 30p. (russian) 